Ankara Üniversitesi Türk Inktlâp Tarihi Enstitüsü Atatürk Yolu Dergisi

S 29-30, Mayts-Kastm 2002, s. 31-38

\title{
85. Yılında Mustafa Kemal Paşa'nın Ankara'ya Gelişi
}

\author{
Doç. Dr. Oğuz AYTEPE*
}

\section{ÖZET}

19 Mayıs 1919'da Anadolu'ya çıkan Mustafa Kemal Erzurum ve Sivas Kongresini yaptiktan sonra stratejik olarak önemli bir yere sahip olan Ankara'ya gelir. İlerde Başkent olacak Ankara Mustafa Kemal tarafindan önce merkez olarak seçilmiştir. Anadolu'nun ortasında olması, demiryolunun Ankara'dan geçmesi, 20. Kolordu'nun Ankara'da bulunması Ankara'ya tartışmasız stratejik bir üstünlük sağlıyordu. Sivas Kongresinden sonra 18 Aralık'ta Sivas'tan ayrılan Mustafa Kemal ve Heyet-i Temsiliye üyeleri Kayseri ve Kırşehir üzerinden dokuz günlük yorucu bir yolculuktan sonra 27 Aralık 1919'da Ankara'ya ulaşır.

Anahtar kelimeler : Mustafa Kemal, Ankara, Heyet-i Temsliye

\section{ABSTRACT}

Mustafa Kemal who arrived in Anatolia on 19 May 1919, came to Ankara, which was a strategicaly important place, after he had held the congresses of Erzurum and Sivas. Mustafa Kemal chose Ankara, which was later going to be the capital, first as a center. The facts that it was in the center of Anatolia, that the railways passed through Ankara, and that the 20th regiment was stationed in Ankara, gave Ankara an undisputable strategic supremacy. Mustafa Kemal and the members of the committee of representatives who left Sivas on 18 December after the Sivas Congress arrived in Ankara on 27 December 1919 after a tyring journey of nine days.

Key words : Mustafa Kemal, Ankara, Committee of Representetive

Birinci Dünya Savaşı sonunda Osmanlı Devleti'nin içinde bulunduğu İttifak grubu yenilmiş, şartları ağır bir ateşkes anlaşması imzalayarak

\footnotetext{
'Ankara Üniversitesi Türk İnkılap Tarihi Enstitüsü öğretim üyesi
} 
savaştan çekilmişti. Millet aralıksız süren savaşlar sonunda yorgun ve fakir bir durumdaydı. Ülkeyi bu hale getirenlerin bir kısmı yurt dışına kaçmış, diğerleri hayatlarını kurtaracak ve tahtı koruyacak önlemler araştırmaktaydı. Ordunun elinden silahları alınmakta, galip devletler birer bahane ile ülkenin birçok bölgesini işgal etmekteydiler. Bu korkunç durum karşısında ülkenin birçok yerinde önlemler alınmaya başlanmıştı. Kurulan cemiyetler bölgesel önlemler almaya çalışıyorlardı. Mustafa Kemal Paşa bu cemiyetlerin aldığı kararlarının hiçbirinde isabet görmüyordu. $\mathrm{O}$ tam bağımsızlıkta direniyor, kurtuluş isteyenlerin parolası "ya istiklal ya ölüm" olmalıdır diyordu. Bu parolayı uygulayabilmek için, Türk yurduna saldıranlara silahla karşı konulacaktı. Uygulama safhalara ayrılacak, milletin duygu ve düşünceleri hazırlanarak adım adım hedefe ulaşılmaya çalışılacaktı. ${ }^{1}$

19. Mayıs 1919'da millet egemenliğine dayanan tam bağımsız bir devlet kurmak amacıyla 9. Ordu Müfettişi olarak Samsun'a çıkan Mustafa Kemal Paşa, bir hafta Samsun'da kaldıktan sonra 25 Mayıs'ta Havza'ya geçti. Tutum ve davranışları nedeniyle padişah tarafından İstanbul'a geri çağırıldı, ancak İstanbul'a dönmeyerek 12 Haziran'da Amasya'ya gitti. Buraya davet ettiği arkadaşları ve diğer yetkililerle anlaşarak Milli Mücadele'nin ihtilâl beyannamesi olan Amasya Genelgesi'ni yayımladı. Milletin bağımsızlığını yine milletin azim ve kararının kurtaracağı ve iki kongrenin açılacağı kamuoyuna duyuruldu.

Mustafa Kemal Paşa 26 Haziran'da Amasya'dan ayrıldı ve Tokat'tan geçerek 27 Haziran'da Sivas'a geldi. Aleyhinde propaganda yapan Elazı ̆ valisi Ali Galip'e iyi bir ders vererek 3 Temmuz 1919' da Erzurum'a geldi. Padişahın kendisini tekrar İstanbul'a çağırdığını ve görevine son verildiğini öğrenince 8/9 Temmuz'da göreviyle birlikte askerlik mesleğinden de ayrıldı.

23 Temmuz 1919'da bir okul salonunda açılan Erzurum Kongresi'ne katıldı ve başkan seçildi. 14 gün süren kongrede; Milli Mücadele'nin hedef ve ilkeleri tespit edildi. Vatanın ve milletin bütünlüğü ve parçalanamayacağ1, geçici bir hükümetin kurulacağı, manda ve himayenin kabul edilmeyeceği, Millet Meclisinin derhal toplanması, milli gücün teşkilatlanmasını sağlayacak kararlar alındı ve kamuoyuna duyuruldu. Bu kararları yürütmek üzere 9 kişilik bir "Heyet-i Temsiliye" seçildi. Başkanlığına da Mustafa Kemal Paşa getirildi. Heyet bir yandan Sivas Kongresinin hazırlıklarını yaparken bir yandan da Kuva-yi Milliye hareketine destek olmuştur. Bu sırada Rauf Orbay ile Mustafa Kemal Paşa'nın yakalanarak İstanbul'a gönderilmeleri hükümetçe istenmişse de 15. Kolordu Kumandanı Kazım Karabekir Paşa bu isteği yerine getirmemiştir.

29 Ağustos 1919'da Heyet-i Temsiliye, Sivas Kongresine katılmak üzere Erzurum'dan ayrıldı. Erzincan boğazını Dersimli eşkiyaların

\footnotetext{
${ }^{1}$ Mustafa Kemal Atatürk, Nutuk, C.I, Milli Eğitim Basımevi, İstanbul, 1973,s. 10 vd.
} 
tuttuğunun bildirilmesine rağmen Mustafa Kemal Paşa'nın aldırdığı önlemler sayesinde heyet 2 Eylül 1919'da Sivas'a geldi.

Sivas'ta beklenen delegeler henüz gelmediğinden kongre 4 Eylül'de açıldı. Kongrenin amacı, tüm ülkenin birlik ve beraberliğini sağlamaktı. Kongrenin ilk günü bazı delegelerin muhalefetine rağmen Mustafa Kemal Paşa başkanlığa seçildi. 11 Eylül'e dek süren Sivas Kongresinde Erzurum Kongresi tüzüğü ve alınan kararlar bazı değişiklikler yapılarak kabul edildi. ${ }^{2}$ Erzurum'da seçilen Heyet-i Temsiliye aynen korunmuş, Heyet-i Temsiliye'ye altı kişi daha seçilerek üye sayısı onaltıya çıkarılmış ve Anadolu ve Rumeli Müdafaam Hukuk Cemiyeti'nin Heyet-i Temsiliyesi haline gelmiştir. Milli Mücadele'nin beyni olan bu heyet T.B.M.M. açılıncaya kadar hükümet gibi çalışmıştır. ${ }^{3}$

Mustafa Kemal Paşa Sivas Kongresi sonunda İstanbul hükümeti ile temas kurmaya çalıştı. Yeni seçilen Sadrazam Ali Rıza Paşa ile anlaşarak Amasya'da 20-22 Ekim 1919'da toplantı yapıldı. Amasya Mülakatı sonunda alınan karara göre İstanbul Hükümeti, Sivas Kongresinde alınan kararları kabul edecekti. Ülkenin bölünmezliği, Meclis-i Mebusan'nın toplanması, Türklerin çoğunlukta olduğu yerlerin işgaline izin verilmemesi gibi hususlarda İstanbul Hükümeti elinden geleni yapacakt1. İstanbul Hükümetinin bir temsilcisinin Amasya'ya giderek Mustafa Kemal Paşa ile görüşmesi, Heyet-i Temsiliye ve milli teşkilatın artık hukuksal olarak Osmanlı Devletince tanındığı anlamına gelmektedir.

Amasya protokolü gereği, Meclis-i Mebusan İstanbul dışında toplanacaktı. İstanbul Hükümetinin buna uymaması nedeniyle Mustafa Kemal Paşa Meclis-i Mebusan'nın toplanacağı yer konusunda kendi başına karar vererek bu kararı millet ve milletvekillerine uygulatmanın tehlikeli olacağını düşünmüş, vereceği kararın uygulanmasını sağlamak için ordunun görüşünü almak istemiş̧i. Bu nedenle bazı kolordu komutanlarını Sivas'a toplantıya davet etti. 16-28 Kasım 1919'da yapılan Komutanlar Toplantısına Heyet-i Temsiliye üyeleri ve birçok kolordu komutanı katıldı. Meclis-i Mebusan'ın İstanbul'da toplanıp toplanmaması sorunu tartışıldı ve Meclis-i Mebusan'ın İstanbul'da toplanmasına karar verildi. ${ }^{4} \mathrm{Bu}$ toplantıda Anadolu'da seçilen mebusların İstanbul'a gitmeden bir araya gelmeleri ve nerede toplanacakları da görüşüldü. Heyet-i Temsiliye'nin Eskişehir yakınlarına taşınması öngörüldü. . $^{3}$ Görüşmelerde Ali Fuat Paşa Eskişehir ve

${ }^{2}$ Tayyib Gökbilgin, Milli Mücadele Başlarkern, C. II, Ankara, Türk Tarih Kurumu Basımevi, 1965, s.9 vd

${ }^{3}$ Bekir Sıtkı Baykal, Heyet-i Temsiliye Kararları, Ankara, Türk Tarih Kurumu Basımevi, 1975, s.IX-X

${ }^{4}$ Bkz, Uluğ Ĭğdemir (Haz.,) Heyet-i Temsiliye Tutanakları, Ankara, Türk Tarih Kurumu Basımevi,1975, s.11-15.

${ }^{5}$ Uluğ İ̆gemir, (Haz.), Heyet-i Temsiliye Tutanaklart, Ankara, Türk tarih Kurumu Basımevi, 1975, s.11. 
Seyitgazi üzerinde durmuş fakat sonunda buluşma yerinin Ankara olması kabul edilmişti. Bu kararın alınmasında, Ankara'da milli teşkilatın çok kuvvetli ve esas savaş alanı olan Batı Anadolu'ya yakın olması, İstanbul'a trenle bağlı olması önemli rol oynamıştı.

$\mathrm{Bu}$ yolculuğun bir süre gizli tutulmasını isteyen Mustafa Kemal Paşa, güzergahın Kayseri ve Kırşehir üzerinden yapılacağını Fahrettin (Altay) Paşa' ya gönderdiği mektupta açıklamıștı. ${ }^{7}$ Mustafa Kemal Paşa karargah olarak Ankara'yı seçmişti. ${ }^{8}$ Bizim tespitlerimize göre, Ankara'nın merkez olması, Erzurum Kongresinin toplandığı günlerde kararlaştırılmış ve bu durum 4 Ağustos 1919'da Mustafa Kemal Paşa tarafından, Ali Fuat Paşa' ya bildirilmişti. ${ }^{9}$

Ankara 15. Kolordu merkezi olmanın dışında, İstanbul'a demiryolu ile bağlıydı ve savaş alanlarına kolayca ulaşılabilirdi. Hükümet yanlısı Vali Muhittin Paşa işbaşından uzaklaştırılmıştı ve güçlü bir Müdafaa-i Hukuk şubesi kurulmuştu.

Kazım Karabekir Paşa Doğu'nun tek başına kalmasından yine karışıklığa düşmesinden korkuyor ve Heyet-i Temsiliye'nin değil Ankara'ya gitmek, Sivas'ın batısına bile geçmesini istemiyordu..$^{10}$

Seçimler yapılıp Meclisin açılmasının zamanı geldiğinde, Mustafa Kemal Paşa Heyet-i Temsiliye'nin Sivas'tan Ankara'ya hareketini 16 Aralık 1919 'da ilgililere bildirmişti. " Sivas'tan ayrılmak için yol hazırlıklarına başlanıldığında para ve benzin sorunları ile karşılaşılmıştı. Kurulun kasasında ancak birkaç lira bulunduğu görülmüştü. Mazhar Müfit Bey bir senet imzalayarak kentteki Osmanlı Bankası Müdürü Oscar Schmitt'en iki bin lira borç alıp yol parası sorununu çözmüştü. Mustafa Kemal Paşa otomobillerde kullanmak üzere 450 kilo benzin ve 60 kilo yağ temin

${ }^{6}$ Mazhar Müfit Kansu, Erzurum'dan Ölümüne Kadar Atatürk'le Beraber, C. II, Ankara, Türk Tarih Kurumu Basımevi, 1968, s, 444 vd.

${ }_{7}$ Taylan Sorgun, Imparatorluktan Cumhuriyete (Fahrettin Altay Paşa Anlatıyor), İstanbul, Kamer Yayınları, 1998,s.199-200.

${ }^{8}$ Mustafa Kemal Paşa Ankara'nın merkez olarak seçilmesini şöyle açıklıyor; "Vaziyet-i umumiyeyi idare ve sevk mesuliyetini deruhte edenler, en mühim hedefe en yakın tehlike, mümkün olduğu kadar yakın bulunur. Yeter ki yakınlık vaziyet-i umumiyeti nazardan mehcur bırakacak derecede olmasın.Ankara bu şeraiti cam'i nokta idi. Her halde cephelerle iştigal edeceğiz diye Balıkesir'e Nazilli'ye veyahut Karahisar'a gitmiyorduk. Fakat cephelere ve İstanbul'a şimendiferlerle merbut ve vaziyet-i umumiyeyi idare nokta-i nazarından Sivas'tan asla farkı olmayan Ankara'ya gelecektik" Bkz., Nutuk, C.I., s.335.

${ }^{9}$ Mustafa Kemal Paşa, "Garbi Anadolu için en büyük merkez ve merciin Ankara olması muvafıktır" diyordu. Bkz, ATASE, (Askeri Tarih ve Stratejik Etüt Başkanlı̆̆ı Arşivi), A.Ö.A., (Atatürk Özel Arşivi), Kl. 4-1, Ds. 335/ 2, Fh. 35 / 3.

${ }^{10}$ Mustafa Kemal Atatürk, Nutuk, C.I, İstanbul, 1973, s.406.; Kazım Karabekir, İstiklal Harbimiz, İstanbul, 1969, s.318.

"ATASE, TiH, (Türk Istiklal Harbi Arşivi), K1. 310. Ds. 44, Fh.48. 
edilmesini Kayseri askere alma dairesi başkanı Emrullah Bey'den rica etmişti. ${ }^{12}$ Oysa ellerinde 3 bidon (56 Kilo) benzinle, yarım kilo solüsyon bulunmaktayd.$^{13}$ Otomobiller için gerekli olan 2 çift iç ve diş lastik ile 6 teneke benzin Amerikan Okulunun müdiresinden sağlanmıștı.

Beş nakliye aracından ibaret Heyet-i Temsiliye ağırlı̆̆ı 13 Aralık 1919 'da bir subay komutasında yola çıkarıld.$^{14}$ Heyet-i Temsiliye de 18 Aralık 1919'da 3 araba ile sabah 9.00'da yola çıktı. Mustafa Kemal ile Heyet-i Temsiliye üyeleri, Mazhar Müfit, Rauf Orbay, Şeyh Fevzi Efendi ve Hakkı Behiç Bey sabah yola çıkanlar arasındaydı. Onların dışında kafilede konuk olarak, Hüsrev Gerede, Dr. Refik Saydam, Ahmet Rüstem ve yaverler, Cevat Abbas Gürer, Muzaffer Kılıç, ve Yüzbaşı Bedri de bulunmaktaydı. Kafile toplam 19 kişiden oluşuyordu. ${ }^{15}$

Ali Fuat Paşa Komutanlar toplantısından Ankara'ya dönerken Heyet-i Temsiliye 'nin geçeceği yerleri ve görüşülecek kişilerle ilgili hazırlık yapmış, heyetin harekatı için gerekli raporu vermişti. ${ }^{16}$

Otomobillerin eski ve bakımsız olması yolda çok zaman kaybetmelerine neden olmuştu. Kayseri'ye ancak iki gün sonra ulaşabildiler. Ali Fuat Paşa 13 Aralık 1919 'da gönderdiği şifrede; yolların hava şartları nedeniyle kötü olduğunu, Rauf Bey'le Mustafa Kemal Paşa'nın Mucur'dan temin edilecek bir araba ile Hacıbektaş'a gitmelerini ve Çelebi Efendi ile görüşmelerini çünkü, tekke babaları ile bu zatın hareketi milliye lehinde olduklarını ve kendisine bu konuda yardım edeceklerini bildiriyordu. ${ }^{17}$ 19/20 Aralık 1919'da gönderdiği telgrafta, “... Çelebi ile Babaların hareketi milliyeyi tasvip ve buna bütün mevcudiyetleriyle iştirak etmelerinin sebebi ziyaret olduğunu (tekrar vurgulamış) Çelebi ile Babaların arası gayet açık olduğundan ona göre idare-i kelam edilmesini" rica etmişti. ${ }^{18}$

Kayserililer onları sevgi ile karşıladılar. Şereflerine fener alayları düzenlediler. İmamzade Reşit Ağa'nın konağında konuk edilen Mustafa Kemal Paşa ve arkadaşları şehrin ileri gelenleriyle görüştü ve milli teşkilatın kuvvetlenmesi için gerekli tedbirleri ald $1 .{ }^{19}$ Heyet-i Temsiliye 21 Aralık 1919 'da Mucur'a geldi, Mustafa Kemal Mucur'da bütün techizat ve iaşesi halk tarafından temin edilen milli süvari müfrezesini görmüş, memnun

\footnotetext{
${ }^{12}$ ATASE, A.Ö.A., K1. 15 , Ds. $335 / 34$, Fh. $4-1$.

${ }^{13}$ ATASE, A.Ö.A, Kl. 15, Ds. $335 / 34$, Fh. 4 - 5

${ }^{14}$ ATASE, A.Ö.A., Kl. 15, Ds. $335 / 34$, Fh. 4- 14.

${ }^{15}$ Heyetin ayrıntılı listesi için bkz., ATASE, A.Ö.A., Kl. 15, Ds. 335/34, Fh. 4 -6.

${ }^{16}$ Ali Fuat Cebesoy, a.g.e., s.259.; 18 Aralıkta Sivas'tan hareket eden Kafile, Kayseri, Mucur, Hacıbektaş, Mucur, Kırşehir, Beynam'dan 27 Aralıkta Ankara'ya ulaşacaktır.

${ }^{17}$ ATASE, A.Ö.A., Kl. 15, Ds. 335 / 34, Fh. $4-13$.

${ }^{18}$ ATASE, A.Ö.A., KI, 15, Ds. 335 / 34, Fh, $4-13$.

${ }^{19}$ Ömer Çelebi, Atatürk Kayseri'de, Ankara, 1973, s.52 v.d.
} 
olmuştu. ${ }^{20}$ Mustafa Kemal Paşa ertesi gün Hacıbektaş'a gitti, Çelebi Cemalettin Efendi ile Post vekili Niyazi Salih Baba, heyete büyük konukseverlik gösterdiler. Cemalettin Efendi sayıları birkaç milyonu bulan Aleviler üzerinde etkiliydi ve ona bağlı idiler. ${ }^{21}$ Mustafa Kemal Paşa ve arkadaşları yemek esnasında görüşmüş ve ondan Kuva-yı Milliyeye taraftar olduğuna dair söz almıştı. ${ }^{22} 23$ Aralık 1919'da Hacıbektaş'tan Mucur'a geçen heyet, ertesi gün Kırşehir'de büyük bir gösteri ile karşılanmıştı. Heyet-i Temsiliye üyeleri Müdafaa-i Hukuk binasıyla birlikte Gençler Derneğini de ziyaret etmişlerdi. Burada gençlere seslenen Mustafa Kemal Paşa örgütlenmenin gereği ve yararı üstünde durmuştu. ${ }^{23}$

Kırşehir'den hareket eden kafile 191 km yolu Ali Fuat Paşa'nın gönderdiği yol krokisinde ${ }^{24}$ gösterdiği 11 konaklama merkezinden geçerek Kaman'a, ertesi günü Beynam'a gelmişti. ${ }^{25}$ Kafile nihayet 27 Aralık 1919'da 9 gün süren yorucu bir yolculuktan sonra 11.00 'de Dikmen sırtlarına ulaşmıştı. ${ }^{26}$

Kafile ilk olarak kendilerini Gölbaşında bekleyen Vali Vekili Yahya Galip Bey ile, 20. Kolordu Komutanı Ali Fuat Paşa'nın yanında durdu ve Mustafa Kemal Paşa karşılayıcılarla görüşerek onları otomobiline aldı ve şehre doğru yollarına devam ettiler.

Ankaralılar Mustafa Kemal Paşa ve Heyet-i Temsiliye üyelerini karşılamaya günlerce önce hazırlanmaya başlamışlar ve O'nu coşkuyla karşılamışlardı. Ankara şehri adına karşılama heyetinde Müftü Hoca Rifat Efendi, Binbaşı Fuat Bey, Kınacızade Şakir Bey, Aktarbaşızade Rasim Bey,

20) Sırrı Kardeş, Heyet-i Temsiliye ve Mustafa Kemal Kırşehir'de, Ankara, Ulus Basımevi, s.9.

${ }^{21}$ Mazhar Müfit Kansu, a.g.e., C.II, s. 493.; Sırnı Kardeş, a.g.e., s.17-18.

${ }^{22}$ Mustafa Kemal Paşa, Ali Fuat Paşa'ya gönderdiği 23.121919 tarihli telde: “ ....bir gün bir gece Çelebi Efendi ve Baba Niyazi Efendi ile müzakere eyledikten sonra bilumum Alevilerle Bektaşiyaanın bütün mevcudiyetleriyle müzahir ve hadim olacaklarına dair vaat ve teminatta bulunduklarını" bildirmekteydi. Bkz., ATASE, A.Ö.A., Kl. 15, Ds. 335 / 34, Fh. 433.

${ }^{23}$ Mazhar Müfit Kansu, a.g.e., C.II, s.495.; Sırnı Kardeş, a.g.e., s.35.

${ }^{24}$ Heyeti takip ettiği yolu ayrıntılı olarak gösteren kroki için bkz, ATASE, A.Ö.A., Kl.29, Ds. $3-13$,Fh. 4 .

${ }^{25} 20$. Kolordu Vekili Mahmut Bey'in 24 Aralık 1919'da Kırşehir'e gönderdiği telde; “ ..kar ve yağmur nedeniyle yollarda çamurun arttı̆̆ı, bu nedenle Ankara'ya hemen gelmenin imkansız olduğunu, tensip buyururlarsa, önce Kırşehir'den Karakaya ve Köprü köyüne varmayı sonra Beynam köyüne gelinerek, Ankara'ya gündüz gözüyle ve öğleden sonra teşriflerinin uygun olacağı... "bildiriliyordu.. Bkz., ATASE, A.Ö.A., Kl. 15, Ds. 335 / 34, Fh. 4-36.; Enver Behnan Şapolyo, Atatürk ve Seymen Alayı, Ankara, 1971, s.25-36.; Ali Fuat Cebesoy, a.g.e., s.265-267.

${ }^{26}$ Mustafa Kemal Atatürk, Nutuk, C.II, s.405.; Mazhar Müfit Kansu, a.g.e., C.II, s.497.; Ali Fuat Cebesoy, a.g.e., s.265. 
Toygarzade Ahmet, Ademzade Ahmet, Hatip Ahmet, Kütüpçüzade Ali, Hanifzade Ahmet ve Bulgurzade Tevfik Beyler vard.

Ali Fuat Paşa, Vali vekili Yahya Galip Bey Gölbaşı'na kadar gelmişlerdi. Binlerce Ankaralı oraya yol boyunca sıralanmıştı. 70 yaya 300 atlı zeybek kıyafetinde seymen yollara dizilmişti. ${ }^{27}$ Atlılar Dikmen'e kadar gitmişler, yayalar ise bugünkü Genelkurmay Başkanlığı önünde toplanmışlardı. İstasyon meydanında jandarma ve polisler de dizilmişlerdi. Heyet Halk Partisi binasının önüne geçip, hükümet binasının önüne geldiğinde, Yahya Galip Bey bir nutukla hoş geldiniz demiş ve hariciye memurlarından Fahrettin Bey de nutuk söylemişti ${ }^{28}$ Mustafa Kemal Paşa ve arkadaşları halkla birlikte Hacıbayram'a kadar yürümüşler ve türbeyi ziyaret etmişlerdi. Hükümet konağında Ankaralılarla konuşan Mustafa Kemal Paşa 15.30 'da hükümet konağına girdi. ${ }^{29}$ Mustafa Kemal Paşa ve Heyet-i Temsiliye üyeleri kendilerine tahsis edilen Kalaba'daki Ziraat Mektebi'ne yerleşti. Yayımlanan bir bildiri ile de Heyet-i Temsiliye'nin geçici merkezinin Ankara olduğu duyuruldu. ${ }^{30}$ Mustafa Kemal Paşa kendisini içtenlikle kabul eden Ankara halkı ile daha yakından tanışmak amacıyla 28 Aralık'ta şehrin ileri gelenlerini Ziraat Mektebine davet etti. Ankaralılarla yaptığı konuşmada ülkenin askeri ve siyasi durumunu anlatmış, Müdafaa-i Hukuk'un amacını belirtmiş ve geleceğe yönelik bazı önemli konulara da değinmişti. İstanbul'a Meclis'e gitmek üzere gelen mebuslarla toplantılar yapan Mustafa Kemal Paşa onlardan Mecliste Müdafaa-i Hukuk Grubu'nu kurmalarını istedi. Anadolu ve Rumeli Müdafaa-i Hukuk Cemiyeti programını Misak-1 Milli olarak hazırladı ve Mecliste kabul edilmesini sağladı. Basının önemini kavrayan Mustafa Kemal Paşa Ankara'da kamuoyunu aydınlatmak amaciyla Hakimiyet-i Milliye gazetesini yayımlamaya başladı.

Ziraat Mektebi bir süre ülkenin ve Milli Mücadele' nin yönetildiği yer olacaktır. Geceleri civar bağlardan gelen silah seslerine, isyancıların Ankara'ya 10-15 saatlik yürüyüş mesafesine kadar yaklaşmış olmalarına, kentte yaşayan muhalif grupların bu durumdan cesaret alarak saldırgan bir tutuma yönelmelerine rağmen Ankaralılar Mustafa Kemal Paşa ve arkadaşlarını, Milli Mücadele'nin yönetildiği bu karargahı korumuşlardır. Onlar da bu kentin insanına duydukları güven nedeniyle kendilerine önerilen karargahı bir başka yere taşıma tekliflerine karşı çıkmışlardır.

Mustafa Kemal Paşa ve arkadaşları, daha sonra güvenlik ve şehre yakınlık açısından daha uygun görülen istasyondaki küçük taş binaya "direksiyon binasına" taşınmış, ancak bu okul Kurtuluş Savaşı süresince,

${ }^{27}$ Enver Behnan Şapolyo, Mustafa Kemal Paşa ve Milli Mücadelenin İ̧ Alemi, İstanbul, Hamle Matbaası, 1967, s.93.

${ }^{28}$ Mazhar Müfit Kansu, a.g.e., C.II, s.497-500.

${ }^{29}$ Atatürk 19 Yıl Önce Bugün Ankara'ya Gelmişlerdi. Ankara, Ulus Basımevi, 1938, s.9.

${ }^{30}$ Mustafa Kemal Atatürk, Nutuk, C.I., s.405.; Mazhar Müfit Kansu, a.g.e., C.II, s.500. 
hatta Cumhuriyetin ilk yıllarında Mustafa Kemal Paşa'nın düşünmek, dinlenmek için yalnız kalabildiği, özel toplantılarını yaptığı bir yer olmuştur. ${ }^{31}$

Ankara'nın merkez olarak seçilmesinin doğru bir karar olduğunu Kurtuluş Savaşı'nın gelişimi göstermiştir. Özellikle Sakarya Meydan Muharebeleri, yer seçiminin başarısını kanıtlamıştır. ${ }^{32}$

Mustafa Kemal Paşa ve arkadaşları olayların olumsuz yönde gelişmesine karşın Ankara'da özledikleri toplumsal dayanışmayı bulmuşlardı. Bu nedenle Ankara, Heyet-i Temsiliye'nin geçici merkezi olmaktan, Türkiye'nin başkenti durumuna yükselecektir.

${ }^{31}$ Bir Zamanlar Ankara, Haz., Demet Börtücene, s.22.

${ }^{32}$ Ankara Ankara, İstanbul, 1994, s.147-148. 